\title{
Investimento externo chinês na América Latina e no Sudeste Asiático: uma análise de escopo, valores e setores-alvo
}

\section{China's foreign direct investment in Latin America and the Southeast Asia: an analysis of scope, values and target sectors}

\section{DOI: $\underline{\text { 10.5752/P.2317-773X.2018v6.n3.p5 }}$}

Bernardo Salgado Rodrigues ${ }^{1}$

Bruno Hendler ${ }^{2}$

Recebido em: 05 de outubro de 2017

Aprovado em: 21 de fevereiro de 2018
1. Doutorando em Economia Política Internacional pela Universidade Federal do Rio de Janeiro, UFRJ-PEPI. Mestre em Economia Política Internacional pela Universidade Federal do Rio de Janeiro, UFRJ-PEPI. Bolsista CAPES. Rio de Janeiro/Brasil.

ORCID: 0000-0002-6439-8359

2. Doutorando PEPI-UFRJ. Mestre em Relações Internacionais pela Universidade de Brasília e doutorando em Economia Política Internacional pela Universidade Federal do Rio de Janeiro. Bolsista CAPES. Rio de Janeiro/Brasil. ORCID: 0000-0003-0896-611X

\section{Resumo}

O artigo tem como objetivo realizar uma análise quantitativa e qualitativa dos fluxos de investimento externo direto (IED) da China em países da América do Sul e do Sudeste (SE) Asiático. A hipótese do trabalho é que os fluxos de IED correspondem a uma lógica de Estado que não obedece, necessariamente, ao imperativo de lucros de curto prazo, uma vez que parte significativa do capital tem origem em fundos e empresas controlados por agentes do governo chinês, e as principais atividades de destino estão ligadas a setores tidos como estratégicos para desenvolvimento e segurança da China no longo prazo. O método da pesquisa está dividido em três partes: levantamento quantitativo dos valores e natureza (pública ou privada) dos fluxos de IED da China em países da AL e SE Asiático; exame quantitativo das principais atividades econômicas ligadas a esses IED's; e cruzamento de dados entre valores, natureza e atividade econômica para propor uma análise qualitativa da relevância dos referidos investimentos para a lógica de Estado da China. Por fim, busca-se refletir sobre as diferenças e semelhanças do perfil de investimento chinês na AL e no SE Asiático, de forma a contribuir para o debate acerca dos impactos da ascensão chinesa nos países em desenvolvimento.

Palavras- chave: investimento externo direto chinês; América Latina; Sudeste Asiático.

\footnotetext{
AbSTRACT

The article aims to conduct a quantitative and qualitative analysis of the flows of foreign direct investment of China in South American and Southeast Asian countries. The working hypothesis is that FDI flows correspond to a State logic that does not necessarily obey the imperative of short-term profits, since a significant part of the capital comes from funds and companies controlled by agents of the Chinese government, and the main target activities are linked to sectors regarded as strategic for China's long-term development and security. The research method is divided into three parts: quantitative survey of the
} 
values and nature (public or private) of China's FDI flows in Latin American and Southeast Asian countries; quantitative examination of the main economic activities related to these FDIs; and cross-data between values, nature and economic activity to propose a qualitative analysis of the relevance of such investments to China's State logic. Finally, the aim is to reflect on the differences and similarities of the Chinese investment profile in Latin America and the Southeast Asia in order to contribute to the debate about the impacts of the Chinese rise in developing countries.

Key words: Chinese foreign direct investment; Latin America; Southeast Asia

Introdução

No início do século XXI, a América do Sul e o Sudeste Asiático aparecem como duas zonas geopolíticas de grande relevância para o desenvolvimento chinês em sua estratégia de abertura e maior influência no mundo. Nesta perspectiva, o Investimento Externo Direto (IED) se apresenta como um fator de análise da influência chinesa em determinados setores econômicos e na sua estrutura de poder.

Diante disso, o artigo tem como objetivo realizar uma análise quantitativa e qualitativa dos fluxos de investimento externo direto da China em países da América do Sul e do Sudeste Asiático. A hipótese do trabalho é que os fluxos de IED correspondem a uma lógica de Estado que não obedece, necessariamente, ao imperativo de lucros de curto prazo, uma vez que parte significativa do capital tem origem em fundos e empresas controlados por agentes do governo chinês, e as principais atividades de destino estão ligadas a setores tidos como estratégicos para o desenvolvimento e a segurança da China no longo prazo.

O trabalho divide-se em três partes: a definição de IED e a participação da China no mundo nos últimos anos; a crescente presença chinesa nas duas regiões em questão através do levantamento e exame quantitativo dos valores e natureza (pública ou privada) e principais atividades econômicas dos seus fluxos; e cruzamento de dados entre valores, natureza e atividade econômica para propor uma análise qualitativa da relevância dos referidos investimentos para a lógica de Estado da China. Por fim, busca-se refletir sobre as diferenças e semelhanças do perfil de investimento chinês na AL e no SE Asiático, de forma a contribuir para o debate acerca dos impactos da ascensão chinesa nos países em desenvolvimento.

China e a internacionalização de capitais

A definição clássica de investimento externo direto segundo a OCDE (p. 17) é: investimento feito por um ator residente em um país A (investidor direto) com o objetivo de estabelecer um "interesse duradouro" em uma empresa fixada em um país B. A motivação desse interesse duradouro em criar uma "relação estratégica de longo prazo" é garantir um grau de influência na gerência da empresa no país B, expresso pelo controle de pelo menos $10 \%$ do poder de voto nos processos de tomada de decisão.

Já Krugman e Obstfeld (1999, p. 172) entendem investimento estrangeiro direto como os fluxos internacionais de capitais pelos quais 
uma empresa em um país cria ou expande uma filial em outro. A característica distintiva do investimento estrangeiro direto é que ele envolve não só uma transferência de recursos, mas também a aquisição do controle. Isto é, a filial não tem apenas a obrigação financeira com a empresa matriz; ela é parte da mesma estrutura organizacional (KRUGMAN; OBSTFELD, 1999, p.172).

O investimento de capital estrangeiro pode ser direto, quando aplicado na criação de novas empresas ou na participação acionária em empresas já existentes; e indireto, quando assume a forma de empréstimos e financiamentos a longo prazo. A expectativa de lucros dos investimentos diretos privados no exterior decorre de fatores como: 1) maiores facilidades fiscais e/ou legislativas do que se conseguiria no próprio país; 2) expectativa de variações cambiais favoráveis 3) ou por temor a mudanças políticas ou fiscais no país de origem. O investimento governamental, por sua vez, é realizado geralmente por razões políticas, diplomáticas ou militares, independentemente de possíveis rendimentos econômicos, mas pode ter a função de equilibrar, em longo prazo, o balanço de pagamentos do país de origem. Para o país receptor, o investimento estrangeiro pode ser um meio de estimular o crescimento econômico quando o nível de poupança interna for insuficiente para atender às necessidades potenciais de investimento, embora isso geralmente acentue o grau de dependência econômica e política do país anfitrião em relação aos países exportadores de capital. (SANDRONI, 2008, p.436-437).

Assim, uma literatura ortodoxa/neoclássica aponta quatro grandes motivações para que uma empresa decida investir no exterior: i) acesso a mercados; ii) redução de custos de produção, geralmente ligados ao barateamento de mão de obra ou de facilidades oferecidas pelo país hospedeiro; iii) acesso a recursos naturais; e iv) acesso a tecnologia e conhecimento técnico (YAO, p. 12-14). Porém, essa concepção se baseia em estudos empíricos sobre a atuação das empresas multinacionais privadas de países desenvolvidos (PD’s), carecendo uma explicação mais realista referente a atuação das SOE's ${ }^{3}$ chinesas. Isto é, o $\mathrm{OFDI}^{4}$ chinês leva em conta, mas não se limita, a esses quatro elementos e, dado o caráter público dessas empresas, argumentamos que parte significativa dos investimentos é motivada por uma lógica estatal que atende a objetivos políticos e estratégicos.

Essa visão heterodoxa é compartilhada por Chesnais (1996). Na sua visão, a análise do IED passa a ser significativa quando se consideram as dimensões qualitativas do IED, destacadas a partir de uma lógica intertemporal que não se reduz a uma transação pontual, de liquidez imediata. Assim, "implica transferências de direitos patrimoniais e, portanto, de poder econômico" (CHESNAIS, 1996, p. 54), que abrange um "componente estratégico evidente na decisão de investimento da companhia" (CHESNAIS, 1996, p.55).

Logo, a "exportação de valor destinado a produzir mais-valia no exterior" (CHESNAIS, 1996, p.50), o que se compreende por IED na atualidade, remete:

(...) a ideia de penetração, seja para depois esvaziar os concorrentes locais, seja para 'sugar' as tecnologias locais, faz parte desse aspecto 'estratégico' do inves-
3. Em inglês, sigla para state owned enterprises.

4. Em inglês, sigla para outward foreign direct investment. 
5. Em inglês, sigla para inward foreign direct investment. timento direto e, geralmente, está inserido num processo complexo de tentar antecipar as ações e reações dos concorrentes. [...] Esse termos remete à existência, no contexto de estruturas de oferta concentradas, de mecanismos de apropriação e de centralização, pelas companhias mais fortes, de ativo ou riquezas produzidos por agentes econômicos. (CHESNAIS, 1996, p.55)

No século XXI, a China se propõe a ser um dos grandes players internacionais buscando projetar poder e gerar riqueza e o IED é parte constitutiva deste processo, tendo no Estado chinês seu principal indutor. Para Fiori (2007, p.32-33),

\footnotetext{
Não há a possibilidade de que algum desses Estados nacionais se transforme em uma nova potência sem dispor de uma economia dinâmica e de um projeto político-econômico expansivo. E fica cada vez mais difícil que algum capital individual ou bloco de capitais nacionais, públicos ou privados, se expanda para fora de suas fronteiras nacionais sem contar com o apoio ativo dos seus Estados, o que só ocorrerá quando esses Estados também tiverem projetos "extraterritoriais".
}

Segundo Fiori (2014, p.31-32), há atualmente uma quarta explosão expansiva no sistema internacional, em que a China se apresenta como o Estado que busca ampliar suas fronteiras globais, buscando novos espaços e territórios de expansão. O seu próprio:

(...) desenvolvimento econômico obedece a estratégias e seguiu caminhos que foram desenhados em resposta a grandes desafios sistêmicos, de natureza geopolítica. Independente de quais fossem as coalizões de interesse, de classe ou de governo, em todos esses países em algum momento formou-se um bloco de poder que respondeu da mesma forma a esses desafios externos, por meio de estratégias e de políticas de fortalecimento econômico sustentadas por longos períodos. (FIORI, 2014, p.37-38)

No caso da China, a partir da abertura econômica em 1978, o país tornou-se um grande receptor de fluxos de IED (IFDI) ${ }^{5}$, oriundos principalmente da diáspora chinesa na Ásia e de PD's. Esse fenômeno, combinado a outros fatores domésticos e externos, trouxe crescimento econômico e desenvolvimento social, mas também acentuou contradições internas que culminaram na gradual transição (a partir dos anos 2000) de um modelo voltado para as exportações aos mercados centrais para outro com comércio e investimentos mais direcionados aos mercados domésticos e de países em desenvolvimento (PED’s). Nesse contexto, a internacionalização de empresas chinesas ganhou a atenção de intelectuais, políticos e empresários do mundo desenvolvido e em desenvolvimento nas últimas décadas.

A contribuição de IED para a inserção chinesa nas cadeias globais de valor (IFDI) é abordada amplamente pela literatura especializada desde os anos 1970. Porém, estudos no sentido oposto, que versam sobre a internacionalização de capitais chineses ganharam força apenas nas últimas duas décadas, diante do crescimento do número de projetos e dos valores envolvidos.Para compreender este fenômeno, cabe-nos uma breve retrospectiva histórica.

A política do governo chinês para a internacionalização de capitais (OFDI) pode ser dividida em três períodos. O primeiro, iniciado em 1979 com a formulação de quinze diretrizes de modernização econômica pelo Conselho de Estado, perdurouao longo da década de 1980 (PEI; ZHENG, 
2015, p. 2). Apenas empresas estatais (SOE's) eram autorizadas a investir no exterior e seus projetos, regulados pelo próprio governo, eram em sua maioria voltados para a facilitação das exportações com a abertura de escritórios no exterior e para os setores de agricultura,mineração e manufaturas (Ibidem).

Foi apenas na segunda fase, iniciada em 1992 com a viagem de Deng Xiaoping para o sul da China, que o governo promoveu reformas jurídicas que facilitariam o registro e a administração de OFDI. Apesar da preponderância das SOE's, empresas privadas e cooperativas também entraram no jogo e diversificaram o perfil e o destino do IED chinês: serviços, saúde, imóveis, seguros e turismo entraram na pauta, além de agricultura, mineração e manufaturas. Assim, o crescimento do número de projetos e dos valores envolvidos nos anos 1990 deveu-se às mudanças domésticas propiciadas pelo crescimento econômico e pela competitividade e know-how de algumas empresas, mas também ao contexto internacional favorável com o avanço da globalização (PEI; ZHENG, 2015, p. 7-8).

O terceiro período iniciou-se no começo dos anos 2000 com a efetivação do plano "going global" do governo chinês, que passaria a apoiar a internacionalização de empresas públicas e privadas, embora a predominância das SOE's continuasse evidente. O principal mecanismo tornou-se a concessão de crédito, com juros abaixo do praticado no mercado, por bancos estatais como o Export-Import Bank of China (China EximBank) (Idem, p. 9). Ademais, a alta taxa de poupança da China e a estrutura corporativa vinculada ao governo combinaram-se ao mercado de capitais distorcido para sustentar o OFDI chinês. Dada a altíssima competitividade do mercado interno, explorado por empresas nacionais e estrangeiras, e o próprio salto de competitividade das firmas chinesas, o OFDI do país deu novo salto nos anos 2000. Assim, as empresas chinesas passaram a investir pesadamente em PD's e PED's mundo afora em busca de mais controle sobre as cadeias de valor e mais acesso a tecnologias, mercados e recursos.

Desta forma, a política externa chinesa passou a conferir alta prioridade ao endosso pragmático das reformas; com diretrizes focadas primordialmente em assegurar condições da segurança e estabilidade para o desenvolvimento (SHI, 2008; SUTTER, 2012; LAI e KANG, 2012; ZHANG, 2012) ${ }^{6}$. Mesmo seus objetivos de segurança nacional se viram cada vez mais permeados por motivação de uma natureza fundamentalmente econômica: forjar um "ambiente internacional pacífico" que suporte ou não coloque empecilhos ao progresso material. Assim, a diretriz chinesa de política externa no novo cenário mundial passou a ser enquadrada como o de "ação dentro da não-ação" (jingzhongyoudong), capturando o princípio de aguardar o timing correto para só então completar um objetivo último em alguma extensão pretendida; nesta lógica, o próprio direcionamento de IED em determinadas localidades geográficas atende aos princípios de desenvolvimento e da política externa chinesa no sistema internacional.

A tabela abaixo apresenta os dados de IED chinês em valores e número de empresas, de 1979 a 2010:
6. Algo justificável em face de sua estratégia de ampliação de exportações objetivando marketshare, e também 0 ímpeto, mais latente apenas na década de 1990, de angariar fluxos de investimento externo direto (IED). 
Tabela 1 - Dados de IED chinês (1979-2010)

\begin{tabular}{c|c|c}
\hline Ano & \# empresas & IED de empresas chinesas (US\$Bi) \\
\hline 1979 & 4 & 0,53 \\
\hline 1980 & 17 & 31 \\
\hline 1983 & 66 & 46 \\
\hline 1986 & 221 & 230 \\
\hline 1989 & 645 & 951 \\
\hline 1992 & 1363 & 1,59 \\
\hline 1995 & 1882 & 1,85 \\
\hline 1998 & 2396 & 2,58 \\
\hline 2001 & 3091 & 4,43 \\
\hline 2004 & 5163 & 44,8 \\
\hline 2007 & + de 10000 & 117,91 \\
\hline 2010 & + de 16000 & 317,21 \\
\hline
\end{tabular}

Fonte: PEl; ZHENG, 2015, p. 5-12.

Em termos proporcionais, o fluxo de investimentos chineses no mundo passa a ser considerável somente a partir de 2008, quando o regime de acumulação da China inicia uma série de transformações estruturais que persistem até hoje e são motivados por fatores externos, como a queda na demanda de PD's, e domésticos, como o salto qualitativo do país nas cadeias globais de valor (CINTRA; PINTO, 2017).

Gráfico 1 - Evolução do Investimento Externo Direto (IED) da China em outros países, 1996-2015 (em US\$ bilhões)

Fonte: The Organisation for Economic Co-operation and Development (2015).

O gráfico abaixo é um retrato geral do OFDI chinês por região. Dele, nota-se uma distribuição relativamente equilibrada entre PED's e PD's ao longo dos últimos doze anos. Porém, se posto numa perspectiva histórica, os PED’s apresentam uma tendência crescente, com destaque para África, Ásia Oriental e América do Sul. 
Gráfico 2 - Distribuição do IED chinês por região

(acumulado 2005-2017, em \%)

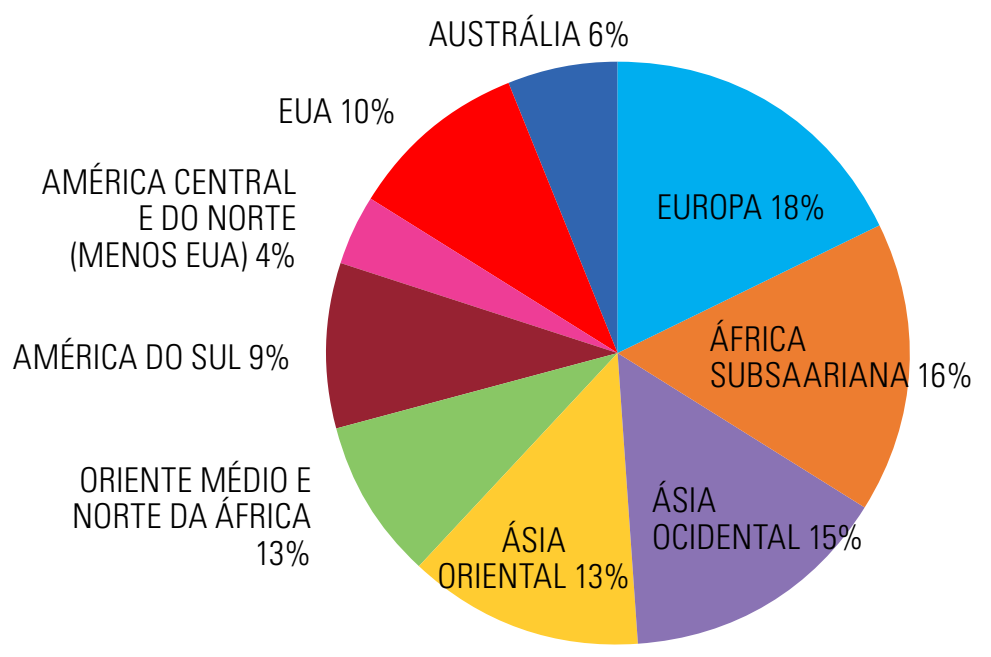

Fonte: The China Global Investment Tracker, American Enterprise Institute, 2017.

Diante disso, nossa tarefa é compreender as motivações dos investimentos das empresas chinesas em duas regiões de grande relevância para o país: Sudeste Asiático e América do Sul. ${ }^{7}$

\section{A expansão quantitativa do IED chinês no Sudeste Asiático}

e na América do Sul

\section{Sudeste Asiático}

Encravado entre o Subcontinente Indiano, o Nordeste Asiático e a Oceania, localizado entre as principais rotas navais do Pacífico e do Índico e berço de um dos principais blocos econômicos da atualidade, o SE Asiático é um dos principais palcos das disputas por poder e riqueza no século XXI. Juntos, os países da Associação das Nações do Sudeste Asiático (ASEAN) respondem por um PIB de US\$ 2,55 trilhões em 2016, segundo a ASEANstats, e têm de lidar com os benefícios e os custos da proximidade com a China - um mercado consumidor em expansão (principalmente de commodities e de produtos industriais de baixo valor agregado), mas também um concorrente de empresas nativas que buscam saltos na cadeia produtiva.

Na esfera geopolítica, o SE Asiático é, também, uma região extremamente dinâmica, pois a ausência de dilemas nucleares faz com que as esferas convencionais de poder militar e de diplomacia tenham margens ainda maiores de atuação e transformação. Por outro lado, a ausência de Estados nucleares significa maior vulnerabilidade às pressões sistêmicas das grandes potências - fosse na Guerra Fria entre URSS e EUA, ou no pós-Guerra Fria entre China e EUA.

A interação da China com os países da região passou por três ciclos recentes (HENDLER; NOGUEIRA, 2016). O primeiro, de 1989 a 1997, foi
7. Compreendemos que os dados sobre IED são problemáticos, sendo necessário uma revisão sobre os limites desses dados inclusive no caso chinês. Por exemplo, parte do IED chinês que vai para a Ásia camufla o fato de que parte considerável das empresas utiliza Hong Kong ou Singapura como praça financeira intermediária, não sendo esse 0 destino final do investimento. Já a América Latina reflete a distorção dos paraísos fiscais, por exemplo. 
marcado pela normalização das relações bilaterais e a gradual redução da projeção dos EUA que, na ausência da URSS, passou a buscar o isolamento de Pequim com base na ameaça remanescente do comunismo e nas violações dos Direitos Humanos em Tiananmen. O segundo, de 1997 a 2008, caracterizou-se pela ofensiva multilateral chinesa, aderindo a normas e organizações regionais para reduzir a percepção de ameaça de sua "ascensão pacífica" e, acima de tudo, pelos empréstimos a juros baixos e valorização do renminbi como formas de resgate às economias do SE Asiático atingidas pela crise financeira de 1997. É também nesse momento que a China se consolida como o duplo pólo na economia mundial (MEDEIROS, 2008, p. 256; 2006), com altíssimos déficits comerciais com o Sul Global (inclusive com o SE Asiático) e superávits comerciais ainda maiores com os países desenvolvidos. Por fim, a atuação chinesa tornou-se ainda mais notória diante da diminuição da presença dos EUA na região, dado o foco na Guerra ao Terror, que deslocou parte significativa das atenções para o Oriente Médio.

Por fim, o terceiro ciclo, ainda em andamento após 2008, tem sido marcado pelo aprofundamento dos laços econômicos entre China e SE Asiático, não apenas comerciais, mas também de investimentos. Se, por um lado, a ASEAN passou de superavitária para deficitária no comércio com a China, por outro, tornou-se um dos principais alvos de IED chinês desde meados da década passada. Diante disso, buscamos compreender se esses investimentos correspondem às quatro motivações clássicas de IED consagradas pela literatura, ou se o elemento político/estratégico é determinante para a execução dos projetos.

Gráfico 3 - IED chinês no SE Asiático (acumulado 2005-2017) Em US\$ Milhões

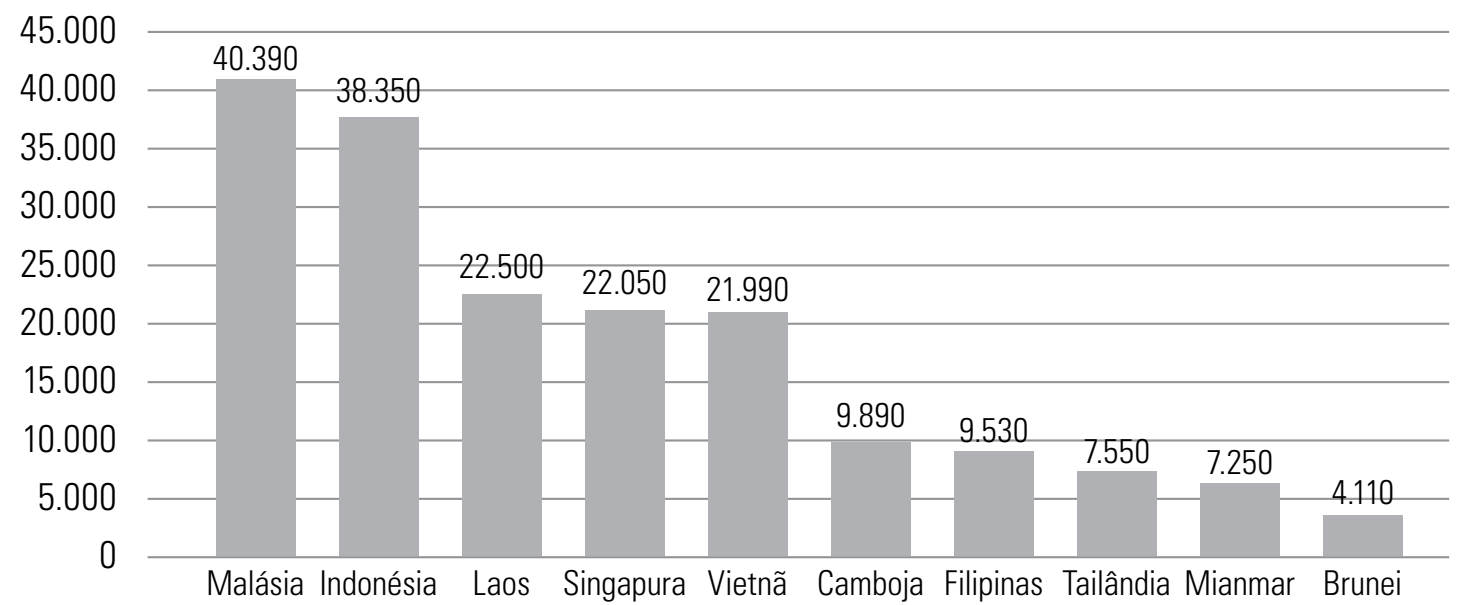

8. Os dados apresentados vão até junho de 2017, quando foi feito o levantamento para esta pesquisa.

Fonte: The China Global Investment Tracker, American Enterprise Institute, 2017.

Conforme o gráfico acima, Malásia e Indonésia foram os principais receptores de IED chinês no SE Asiático entre 2005 e $2017^{8}$, seguidos por Laos, Singapura e Vietnã. O gráfico abaixo apresenta esses números em termos proporcionais, por país. 
Gráfico 4 - Proporção do IED chinês no SE Asiático por país

(acumulado 2005 a 2017)



Fonte: The China Global Investment Tracker, American Enterprise Institute, 2017.

No caso da Indonésia, dos US\$ 38 bilhões investidos, cerca de US\$ 22 bilhões estão ligados ao setor energético, dos quais US\$ 15 bilhões apenas no ramo do carvão. Isto é, $40 \%$ do IED chinês tem como destino a exploração deste recurso, que é exportado majoritariamente para a própria China (SPRINGER, 2016). O Vietnã é outro país que se destaca como receptor de IED chinês no setor de carvão: cerca de US\$ 12 bilhões do total de US\$ 21 bilhões. Diante disso, nota-se uma convergência entre o acesso a recursos energéticos e o imperativo estratégico chinês de preencher a lacuna entre a geração e a demanda por energia do país.

O gráfico abaixo apresenta a parcela do setor energético sobre o total do IED da China nos países da ASEAN. Países como Brunei, Filipinas, Laos e Vietnã chamam a atenção pela alta proporção de investimentos chineses em energia, ainda que a Indonésia esteja acima, em valores absolutos.

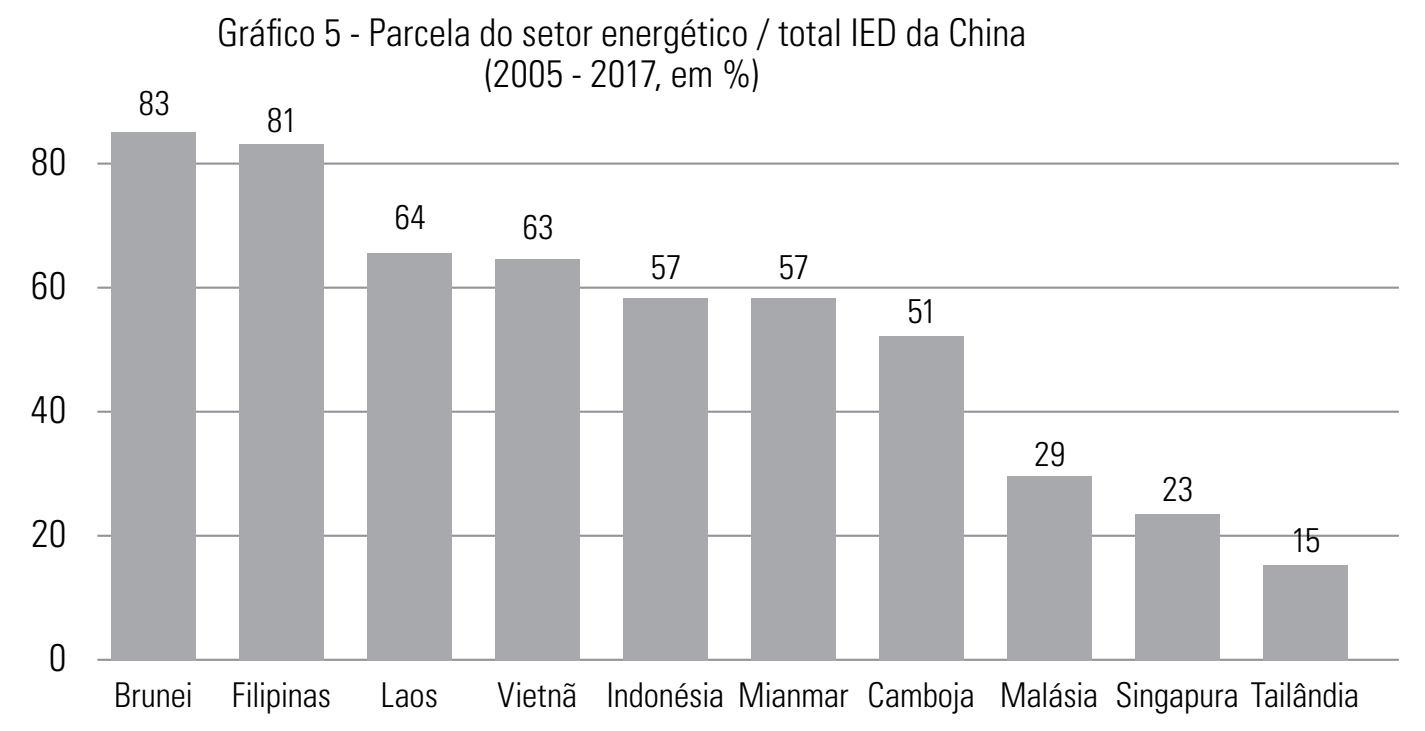

Fonte: The China Global Investment Tracker, American Enterprise Institute,2017. 
Assim, o setor energético responde a praticamente metade de todo o IED da China no SE Asiático de 2005 a 2017. Outros setores que se destacam são: transportes (19\%), imóveis (11\%) e metais (10\%), conforme o gráfico abaixo.

\section{Gráfico 6 - IED da Cinha no SE Asiático: participação por setor econômico} (média acumulada, 2005-2017)

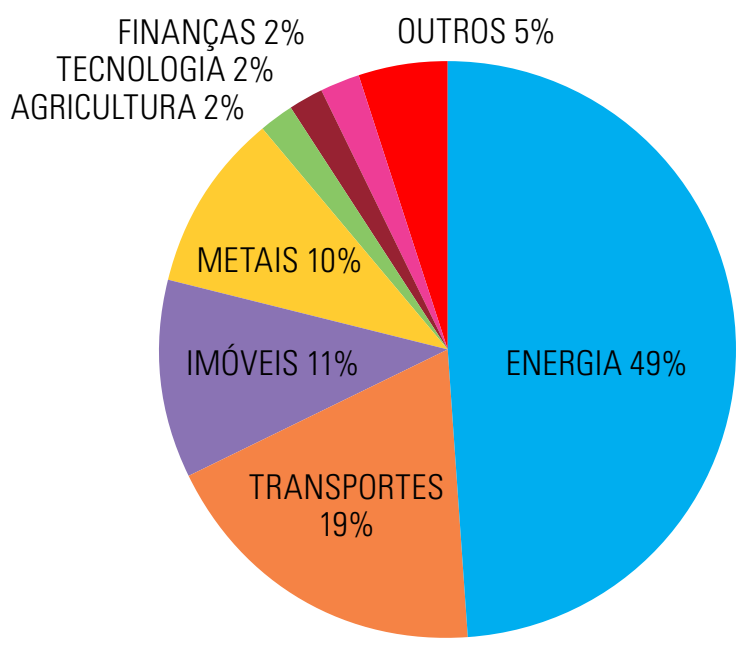

Fonte: The China Global Investment Tracker, American Enterprise Institute, 2017.

Nota-se que o IED chinês no setor energético atua em duas funções distintas. No Vietnã e na Indonésia o objetivo principal é investir na exploração de carvão para importá-lo e atender a demanda doméstica - ainda que essa tendência esteja diminuindo dada a busca chinesa por energias renováveis (SPRINGER, 2016). Já nos países que compartilham trechos extensos do Rio Mekong, Laos e Camboja, o IED chinês tem como destino a construção de usinas hidrelétricas para abastecer os mercados domésticos. Ambos os processos, mas principalmente o segundo, tendem a acentuar a interdependência assimétrica entre a China e seus vizinhos e moldar a percepção das elites locais sobre a ascensão do gigante asiático (SAMBATH, sem data). Por fim, no caso das Filipinas, há investimentos tanto em carvão quanto em hidrelétricas, que respondem por parte relevante do IED chinês, mas os valores absolutos são baixos, se comparados aos países já citados.

A Indonésia é também um dos principais alvos de IED em número de projetos, conforme o gráfico abaixo (79 no total). Porém, o salto a partir de 2010 refletiu uma mudança fundamental nos setores-alvo. O carbonífero, que correspondia a 84\% do total de IED de 2005 a 2009 (US\$5,9 bilhões do total de US\$ 7 bilhões), passou a representar apenas $20 \%$ de 2010 a 2013 (US $\$ 2,1$ bilhões de US\$ 10,5 bilhões) e depois subiu para 47\% de 2014 a 2017 (US\$ 7,8 bilhões de US\$ 16,5 bilhões). Em contrapartida, setores como construção, transportes e aço, ganharam mais relevância com uma quantidade maior de projetos.

Esses investimentos têm em comum a origem em SOE's chinesas, o que nos leva a refletir sobre seus objetivos. Dos cerca de US\$ 180 bilhões de dólares de IED chinês no SE Asiático de 2005 a 2017, cerca de 90\%, são de 
empresas estatais. Além dos investimentos corresponderem a uma lógica econômica em sua zona de influência imediata, em que empresas chinesas e de Empresas Transnacionais (ETN's) com sede na China deslocam partes de suas cadeias produtivas em busca de redução de custos, agregam-se fatores político/estratégicos para a execução dos projetos. Um dos mais relevantes é a cooperação na Bacia do Rio Mekong. Por meio de investimentos da China em megaprojetos de infraestrutura, a região que abrange Laos, Camboja Vietnã, Tailândia e Mianmar tem apresentado um aprofundamento na integração de atividades econômicas (PINTO, 2015 p. 85-87).

\section{GRÁFICO 7 - IED da China na Indonésia (número e valor dos projetos)}

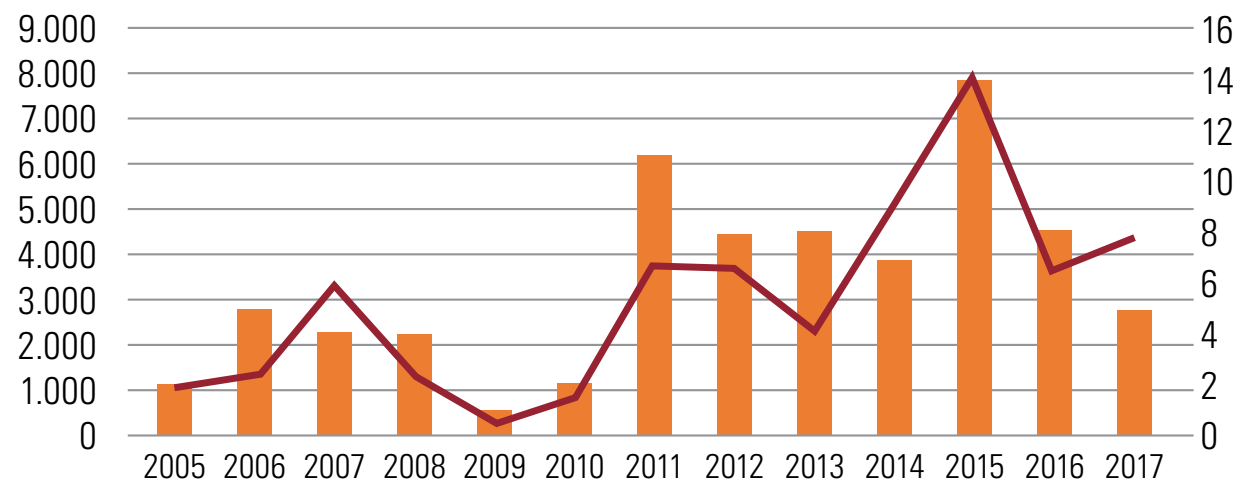

Número de projetos $\quad$ Valor dos projetos (em US\$ mil)

Fonte: The China Global Investment Tracker, American Enterprise Institute, 2017.

Há também o fenômeno do China plus-one, definido como o recente processo em que multinacionais chinesas e estrangeiras (americanas, europeias, japonesas e coreanas) instaladas na China deslocam parte de suas plantas produtivas para países da ASEAN fronteiriços da China, mantendo parte de suas operações no território chinês, garantindo vínculos com esse importante mercado consumidor e reduzindo os custos de produção (PINTO, 2015, p. 85).

A ocupação de espaços estratégicos também se realiza pela diplomacia, movida pelo temor de surgimento de uma aliança antichinesa liderada pelos EUA (LI, 2009, p. 18). Visitas de políticos, diplomatas de alto escalão, militares e acadêmicos ao SE Asiático são cada vez mais frequentes, geralmente reiterando o discurso da boa vizinhança e da construção de um ambiente de confiança mútua, tão prezado pelos membros da ASEAN. Ademais, no âmbito multilateral, a China foi o primeiro país a criar uma representação permanente para esta organização.

No entanto, a retórica da boa vizinhança e da cooperação bi e multilateral choca-se com a postura chinesa no tocante aos litígios territoriais envolvendo Filipinas, Vietnã, Brunei, Malásia e Taiwan no Mar do Sul da China. A percepção da China como uma ameaça por esses países é fortalecida pelo contexto de modernização das forças armadas, pela atuação belicosa da marinha chinesa ao lidar com barcos pesqueiros estrangeiros em áreas em disputa e pela construção de bases militares e povoamentos civis em ilhotas na região (ACHARYA, 2009). 
9. Tais Cinco Princípios constituem eixos norteadores fundamentais para a política externa chinesa, possuindo alta resiliência desde o período da economia maoísta planificada até décadas depois da transição. Ganharam "corpo" com a visita de Zhou Enlai a Índia e Burma onde publicou comunicados conjuntos advogando-os, e posteriormente endossando-os na famosa Conferência de Bandung (1955). São eles: respeito mútuo pela soberania e integridade das outras nações; não-agressão mútua não-interferência mútua nos assuntos internos de cada país; equidade e cooperação em prol do benefício mútuo; e, finalmente, coexistência pacífica (ZHANG, 2012: p.59-61).
Os investimentos militares da China, embora cresçam no mesmo ritmo de expansão da economia e representem hoje cerca de $2 \%$ do PIB, agravam a percepção de ameaça na região, principalmente pelas altas cifras em valores absolutos. Ademais, criam a sensação de que, mais cedo ou mais tarde, a periferia econômica da China tornar-se-á também uma periferia geopolítica em que os EUA terão gradualmente menos influência (HENDLER; NOGUEIRA, 2016, p. 217). Portanto, ao "amarrar" os vizinhos do SE Asiático à sua dinâmica econômica por meio de investimentos, a China tende a moldar percepções e comportamentos da região a seu favor e este é um processo em aberto que tende a se tornar ainda mais complexo.

\section{América do Sul}

A presença chinesa na América do Sul se fez atuante a partir do momento em que o gigante asiático desenvolveu sistematicamente relações comerciais e diplomáticas mais aprofundadas com a região após sua adesão à Organização Mundial do Comércio (OMC), em 2001. Assim, engajou-se de modo a expandir interações e fortalecer suas próprias reformas em curso, tendo como exemplo, ao longo dos últimos anos, a assinatura de inúmeros acordos intergovernamentais com mais de vinte nações latino-americanas e o desenvolvimento de relações bilaterais mediante parcerias estratégias como a APEC (Asia Pacific Economic Cooperation) e CELAC (Comunidade de Estados Latino-Americanos e Caribenhos) em anos mais recentes.

Como bem salientam Tsai e Liu (2012), desde iniciativas como a visita do Ministro das Relações Exteriores chinês, Tang Jiaxuan, em 2001 no Chile, apregoando a cooperação Sul-Sul e preparando terreno para o fortalecimento das trocas inter-regionais, o processamento do comércio exterior chinês foi turbinado. Isto fez da América do Sul uma das principais regiões receptoras de IED da China, com perspectivas de crescer ainda mais, demonstrando o intenso apreço estratégico que Beijing guarda pela região, algo corroborado pelos marcos das duas visitas do presidente Hu Jintao ao continente, em 2004 e em 2008.

Em termos específicos de relações de política exterior para com a América do Sul, o presidente chinês Yang Shangkun (1988-1993) expressou, em sua visita ao continente nos anos 1990, o que assinalou como "quatro princípios" latentes para tal aliança: que ambas as partes estabeleceriam relações cooperativas amigáveis com base nos Cinco Princípios de Coexistência Pacífica'; que tanto o comércio bilateral quanto a cooperação econômica e tecnológica fossem expandidos pelo interesse mútuo; que ambas as partes respeitem os valores e tradições culturais de cada um; e, finalmente, que empreendessem esforços conjuntos visando lograr uma nova ordem política e econômica internacional, mais multipolar, consultiva, e menos assimétrica (TSAI e LIU, 2012: p.292-3).

Dentre os eixos norteando a maior aproximação chinesa, figuram as motivações de cultivo a um mercado consumidor considerável para seus produtos; a busca de apoio para alavancar agendas estratégicas diversas no âmbito das instituições multilaterais; e a segurança energética. 
Diante do notável crescimento das relações comerciais, em 2008, o governo chinês publicou o primeiro policy paper referente à região, conhecido como "Livro Branco da China para a América Latina", denotando pilares primordiais das relações com o continente, que, pelo menos em termos retóricos, deveriam se basear na equidade e na cooperação mutuamente benéfica. Em seguida a tal documento, o padrão de investimentos foi revigorado, com montantes ainda maiores de inversões no continente e no Cone Sul em especial. O principal mote ao qual se orienta o IED chinês é o setor de hidrocarbonetos, seguido pelo de mineração e todas as outras atividades primárias ${ }^{10}$.

Desta maneira, os investimentos diretos da China na região vêm se destinando à compra de matérias primas e formação de joint-ventures na aquisição de licenças de exploração de recursos naturais e, em casos de obras de infraestrutura, para atuação de empresas transnacionais em aliança com estatais chinesas. Para Moreno (2015, p.33-34), evidencia-se "a oportunidade que a América Latina oferece apenas para provisão de matérias-primas, na contramão do que seria uma relação mais equitativa, que potencializasse o comércio intra-industrial”. As exportações latino-americanas para a China, assim como os investimentos chineses na região, estão concentrados em commodities - especialmente commodities extrativas - em comparação ao resto do mundo.

A China tem sido um motor importante na expansão da exportação de bens agrícolas e extrativos da América do Sul. Como mostra a figura abaixo, enquanto as exportações agrícolas e extrativas para a China cresceram como proporção do PIB, essas exportações para o resto do mundo permanecem estagnadas ou mesmo caíram durante a última década. A demanda chinesa também desempenhou um papel no aumento do nível geral da maioria das commodities durante o período, aumentando significativamente os termos de troca em favor da América Latina. (RAY et al, 2015).

Gráfico 8 - Composição da pauta exportadora da América Latina por setor
10. As características gerais do IED chinês na região são descritas, conforme Slipak, da seguinte forma: orientação para o longo prazo e segurança de recursos; estabelecimento de firmas chinesas com pouca ou nenhuma transferência de tecnologia aos países de destino; ausência de condicionalidades; ausência de promoção de uma agenda específica por parte do País do Meio; e, finalmente, obras de infraestrutura trazendo consigo a obrigatoriedade de firmas de origem chinesa e provisão de insumos e produtos intermediários de determinado valor agregado (SLIPAK, 2014, p.111).

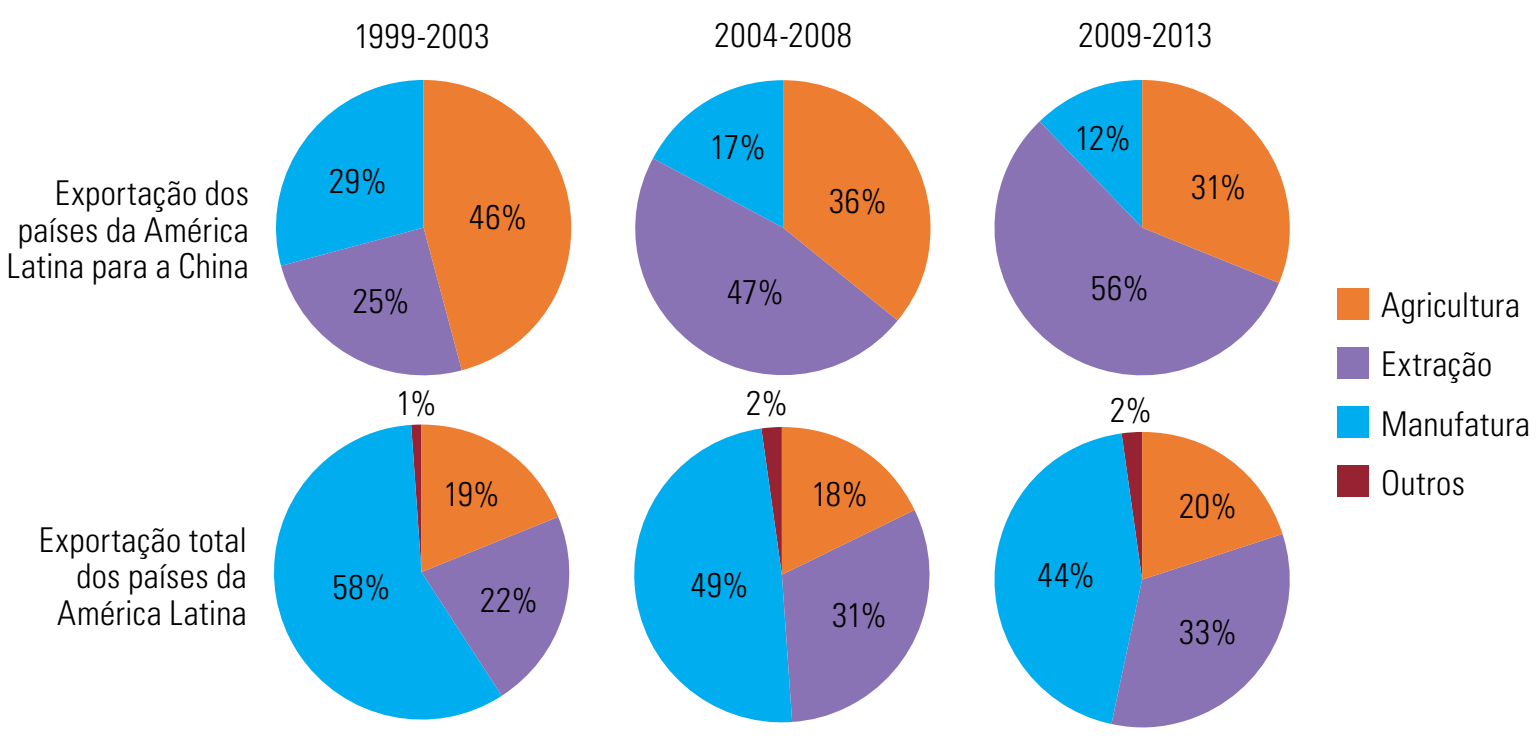

Fonte: RAY et al , 2015. 
11. By far and away the largest Chinese investments in Latin America are in the energy and mining sectors. With just a few exceptions these investments are dominated by China's "big three" large state-owned firms - China National Petroleum Corporation (CNPC), China National Offshore Oil Corporation (CNOOC), and the China Petroleum and Chemical Corporation (SINOPEC) which are backed by finance from the CDB [...] and the larger government apparatus enabling China's go out policy. (GALLAGHER, 2016, p.53)
A China vem expandindo de forma expressiva o investimento direto especialmente na segunda metade da década de 2000 , cujo interesse primordial tem sido voltado aos recursos naturais e energia (petróleo, cobre e ferro). O IED chinês na América Latina ficou concentrado, sobretudo, no setor de energia (54,6\% do total acumulado entre 2005 e 2013), sendo que deste valor $40 \%$ foram direcionados ao segmento do petróleo. As participações de outros setores de atuação das empresas chinesas na América Latina foram: $17,7 \%$ em metais; $14 \%$ no setor de transporte (automóveis); 4,6 \% na agricultura; 4,5\% em imóveis.

De longe, os maiores investimentos chineses na América Latina estão nos setores de energia e mineração. Com apenas algumas exceções, esses investimentos são dominados pelas "três grandes" empresas estatais chinesas - China National Petroleum Corporation (CNPC), China National Offshore Oil Corporation (CNOOC) e China Petroleum and Chemical Corporation (SINOPEC) - que são apoiados por financiamento do CDB [...] e pelo aparato maior do governo que permite a política de saída da China. (Tradução nossa) ${ }^{11}$

Gráfico 9 - IED da China na América Latina: participação por setor econômico (média acumulada, 2005-2017)

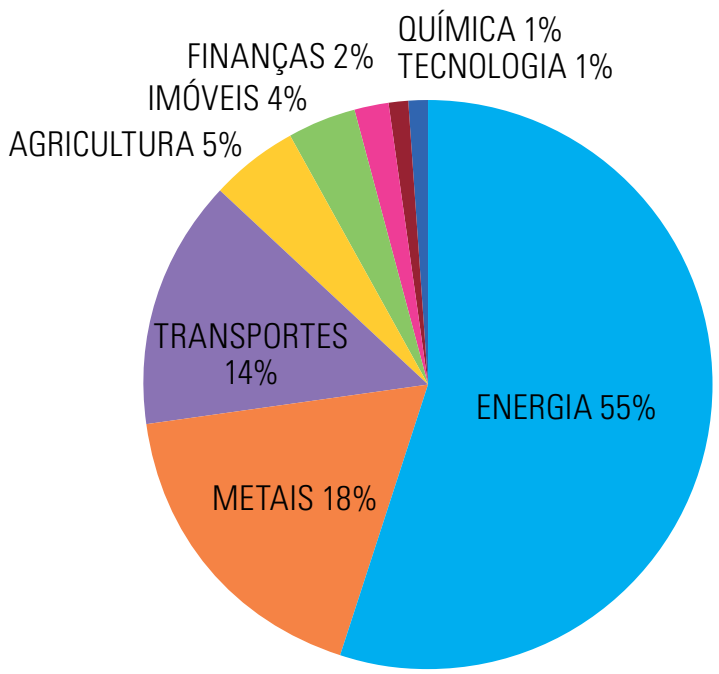

Fonte: The China Global Investment Tracker, American Enterprise Institute,2017.

Evidencia-se a estratégia chinesa de garantir o acesso às fontes de recursos naturais entre 2005 e 2013 (RAY et al, 2015). A América do Sul é o destino principal dos IED chineses, que podem ser divididos em três principais categorias, de acordo com seus propósitos: a) "orientados aos recursos naturais" (natural resource-seeking); b) "orientados ao mercado" (market-seeking) e c) "orientados à eficiência" (efficiency-seeking). A grande maioria dos IED com destino à América do Sul são orientados à exploração de recursos naturais, em setores de grande demanda da China, como cobre, aço, petróleo e soja. Ademais, pode-se observar investimento em infraestrutura ligados a facilitar o escoamento desses produtos. (VADELL, 2011)

A América do Sul tornou-se um dos alvos do IED chinês, recebendo cerca de US\$ 144 bilhões, ainda abaixo Europa (US\$ 291 bilhões), África Subsaariana (US\$ 271 bilhões) e da Ásia Ocidental (US\$ 240 bilhões), no acumulado 2005-2017. A tabela abaixo apresenta a evolução do IED chinês na América do Sul em valores e pelo número de projetos individuais acima de US\$ 100 milhões. 


\section{Gráfico 10 - IED da China na América do Sul}

(valores e número de projetos)

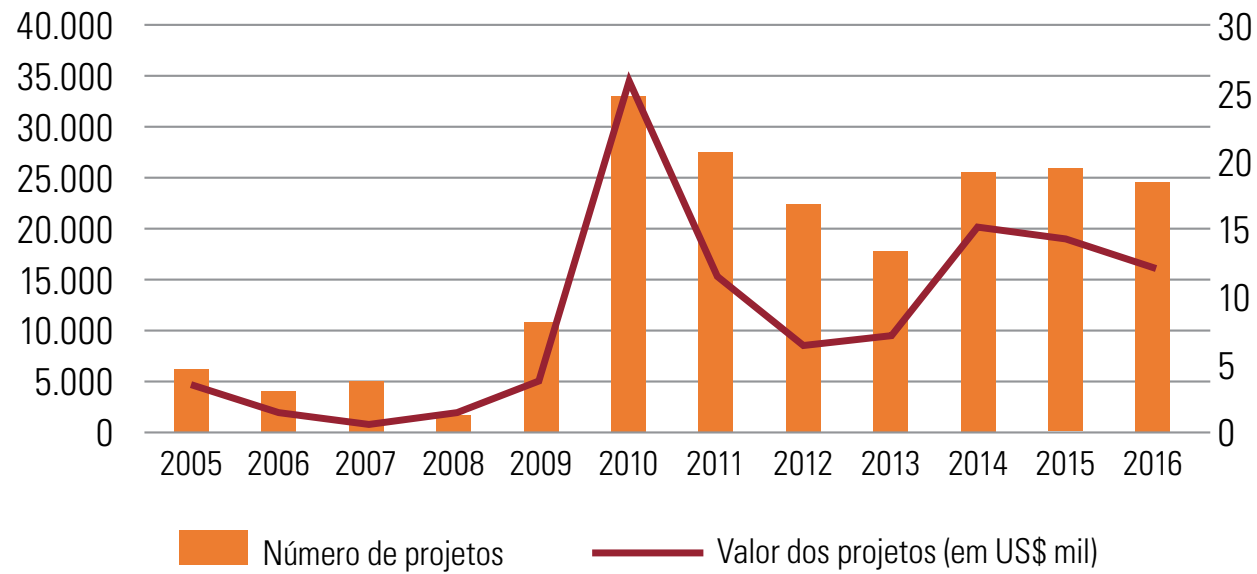

Fonte: The China Global Investment Tracker, American Enterprise Institute, 2016.

Do total, cerca de um terço (US\$ 52 bilhões) teve como destino o Brasil, em especial o setor energético (US\$ 38 bilhões). Além do Brasil, Argentina (US\$ 27,4 bilhões), Venezuela (US\$ 20,6 bilhões) e Peru (US\$ 19,6 bilhões) também se destacaram como receptores de IED chinês. Os setores alvo foram praticamente os mesmos: energia, transportes e mineração.

Gráfico 11 - IED da China na América do Sul mais México (2005-2017, US\$ milhões)

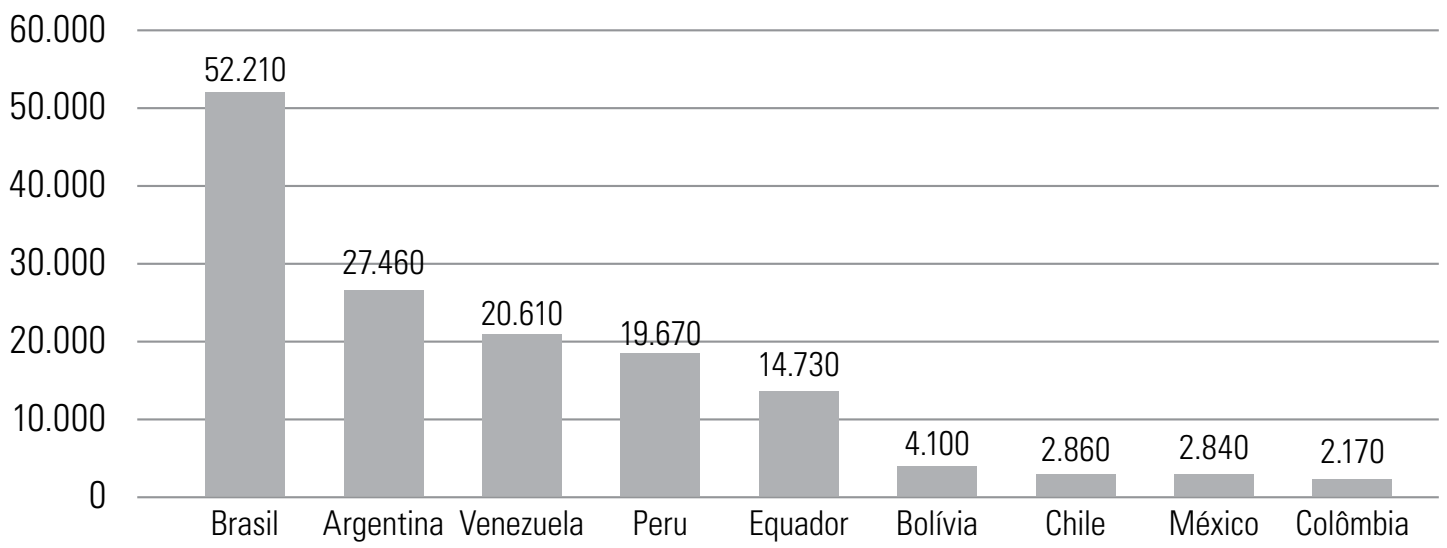

Fonte: The China Global Investment TrackerAmerican Enterprise Institute, 2017.

Entre 2005 e 2017, o IED chinês destinado a América do Sul correspondeu a cerca de US\$ 144 bilhões de dólares. Desse total, aproximadamente $90 \%$ foram realizados por empresas estatais (SOE's) (The China Global Investment Tracker, American Enterprise Institute), ratificando um domínio "by state-owned enterprises rather than by private sector multinationals" (GALLAGHER, 2016, p.52).

Como pode ser observado ao analisar a proporção de IED estatais e privados tanto na América do Sul como no Sudeste Asiático, confirma-se uma tendência no que tange ao destino, escopo e setores-alvo do IED chinês. Neste contexto, a América do Sul vem representando um novo 
espaço de expansão dos investimentos chineses no mundo, uma nova fronteira capitalista que, pelo seu histórico déficit de infraestrutura, converge com a estratégia de exportação de capitais chineses para esse fim, inclusive ao alinhar-se ao acesso privilegiado de recursos naturais que a região possui e que são de interesse geoestratégico para a China no médio-longo prazo.

Análise qualitativa do IED chinês no Sudeste Asiático e na América do Sul

No sistema internacional, a produção e a riqueza interna de cada país são condições indispensáveis de poder e expansão internacional, uma vez que "o poder político é fluxo, mais do que estoque" e necessita "se reproduzir e ser acumulado permanentemente" já que é o ato da conquista "a força originária que instaura e acumula o poder" (FIORI, 2007, p. 17-18). Assim, prevalece um sistema anárquico e altamente competitivo, com economias nacionais que lutam entre si afim de aumentar a riqueza nacional, no qual a conquista de territórios econômicos supranacionais cada vez mais extensos consiste num imperativo de acumulação, onde seus capitais possam ocupar posições monopólicas e obter "lucros extraordinários" (FIORI, 2007, p. 29-30).

Os Estados líderes no sistema internacional possuem uma visão estratégica e expansionista de suas economias nacionais, visando uma luta permanente de ampliação de seus territórios econômicos supranacionais no campo do poder: utilizam-se dos seus bancos, do comércio, das finanças e do investimento estrangeiro direto com a finalidade de ajustamento econômico interno e externo. O estudo de caso do IED chinês no Sudeste Asiático e na América do Sul demonstra e ratifica esta visão. "A luta dessas grandes potências parece quase inseparável da luta pela expansão continua do seu território econômico supranacional e pelo controle monopólico de novos mercados, de bens, créditos ou investimentos." (FIORI, 2014, p. 40).

O IED analisado sob uma perspectiva geoeconômica corresponde a um ato de força fundamental para a reprodução do poder do Estado A sobre o território e a população do Estado B. Em outros termos, é a expansão do investidor direto numa relação estratégica de longo prazo, garantindo influência não somente econômica (através de fluxos de capitais), mas geopolítica (através de interesses políticos) na gerência de empresas do Estado B.

Os dados do IED chinês no mundo são significativos para a compreensão desta nova etapa de acumulação de poder e riqueza fora das suas fronteiras nacionais: em 2013, a China possuía o segundo maior estoque de investimento estrangeiro direto no mundo, com aproximadamente 1.8 trilhão de dólares (GALLAGHER, 2016, p.35); em 2014, os bancos de desenvolvimento chineses provisionaram mais financiamento para a América Latina do que o Banco Mundial, o BID, e o US Export-Import Bank (US Ex-Im) juntos (GALLAGHER, 2016, p.65); em 2015, a China se comprometeu a realizar empréstimos de 20 bilhões para a cooperação infraestrutural latino-americana, 10 bilhões em em- 
préstimos preferenciais, 5 bilhões em um fundo de cooperação, todos nos marcos da cooperação China-CELAC. (GALLAGHER, 2016, p.87). Esta estratégia possui duas motivações:

\begin{abstract}
A China acumulou uma enorme reserva de riqueza e poupança que busca diversificar grandes investimentos em todo o mundo. Em segundo lugar, a China se sente menosprezada pelo Ocidente por não ter recebido um papel maior nas instituições de Bretton Woods. [...] Desde que a China não entrou nas instituições existentes, começou a criar as suas próprias. Essas instituições agora têm à sua disposição níveis de capital que rivalizam com os do banco de desenvolvimento apoiado pelo Ocidente. O Banco Mundial possui pouco mais de US \$200 bilhões em capital e possui pouco mais de US $\$ 500$ bilhões em ativos. O CDB detém US $\$ 100$ bilhões em capital e possui mais de US $\$ 1$ trilhão em ativos. O CDB e o CHEXIM fornecem agora mais empréstimos a governos latino-americanos do que o Banco Mundial e o Banco Interamericano de Desenvolvimento - e mais empréstimos para a Ásia do que o Banco Mundial e o Banco Asiático de Desenvolvimento. (GALLAGHER, 2016, p.189, tradução nossa) ${ }^{12}$
\end{abstract}

Ainda, a crise de 2008, que afetou a demanda de PD's por manufaturados chineses, acentuou a tendência de sofisticação dos laços da China com o mundo em desenvolvimento. O comércio bilateral com países do SE Asiático e da América do Sul vem crescendo substancialmente, dada a demanda chinesa por produtos primários para abastecer indústrias e mercados domésticos. Ademais, ao se tornar um "duplo polo" na economia global, a China substituiu os EUA como principal parceiro comercial de uma parcela majoritária do mundo em desenvolvimento.

Seguindo a diretriz do "going global", a China tornou-se não apenas receptora, mas também grande "exportadora" de IED a partir de meados dos anos 2000. "Between 2002 and 2013 China's overseas foreign direct investment flows grew from $\$ 2.7$ billion to $\$ 90$ billion and are predicted to out strip inward foreign investment in 2015." (GALLAGHER, 2016, p.52) O acúmulo de reservas estrangeiras a partir do superávit comercial das décadas anteriores tem pressionado o governo chinês a incentivar a internacionalização de capitais (OFDI) para conter tendências inflacionárias e reciclar capitais em atividades produtivas. Além disso,

\footnotetext{
Inicialmente, a China bloqueou as operações no exterior de suas empresas, a fim de preservar as reservas cambiais e priorizar o desenvolvimento da China continental. Tudo isso mudou em 2001, quando o primeiro- ministro chinês Zhu Rongji recomendou que a China embarcasse em uma estratégia de "saída" que encorajasse suas principais firmas a investir no exterior e a fazer contratos globais como parte do décimo plano quinquenal de seu país. O primeiro- ministro disse: precisamos implementar uma estratégia de "sair", encorajando empresas com vantagens comparativas a fazer investimentos no exterior, a estabelecer operações de processamento, a explorar recursos externos com parceiros locais, a contratar projetos de engenharia internacionais e aumentar a exportação do trabalho. Precisamos fornecer uma estrutura de política de apoio para criar condições favoráveis para que as empresas estabeleçam operações no exterior. (GALLAGHER, 2016, p.50, tradução nossa) ${ }^{13}$
}

Porém, dado que parte significativa desses fluxos está ligada a empresas estatais, é preciso repensar o conceito de "relação estratégica de longo prazo". Logo, partimos da premissa de que, ainda que se enquadrem na categoria de IED, as operações de ETN's privadas como a Apple e de SOE's chinesas, como Sinopec (petróleo), China Railway Engineering (transportes) e Power Construction Corp. (energia) tendem a obedecer a lógicas distintas. Assim, uma análise do IED chinês no SE Asiático e na
12. China has accumulated an enormous store of wealth and savings that it seeks to diversify by making big investments across the world. Second, China feels slighted by the West for not being given a greater role in the Bretton Woods institutions. [...] Since China wasn't let into existing institutions, it has begun to create its own. These institutions now have levels of capital at their disposal that rival that of the Western- backed development bank. The World Bank holds just over $\$ 200$ billion in capital and has just over $\$ 500$ billion in assets. The CDB holds $\$ 100$ billion in capital, and has over $\$ 1$ trillion in assets. The CDB and CHEXIM now provide more loans to Latin American governments than the World Bank and the Inter- American Development Bank - and more loans to Asia than the World Bank and the Asian Development Bank.

13. China initially blocked overseas operations of its companies in order to preserve foreign exchange reserves and to prioritize the development of mainland China. That all changed in 2001 when Chinese Premier Zhu Rongji recommended that China embark on a "going out" strategy that would encourage its flagship firms to invest abroad and bid for global contracts as part of his country's Tenth Five- Year Plan. The premier said: we need to implement a "going outside" strategy, encouraging enterprises with comparative advantages to make investments abroad, to establish processing operations, to exploit foreign resources with local partners, to contract for international engineering projects, and to increase the export of labor. We need to provide a supportive policy framework to create favorable conditions for enterprises to establish overseas operations. 
14. the key engine of the go out strategy is financial support by the CDB and the

China Exim Bank, at least when it comes to the activities of large state-owned and state supported firms that make up the bulk of China's overseas foreign direct investment (FDI).
América do Sul, que é majoritariamente estatal, enseja a interpretação de um padrão de investimento chinês que esteja mais voltado para interesses estratégicos de Estado do que de lucro de mercado, ou, como afirma Gallagher (2016, p.51, tradução nossa) "o principal motor da estratégia de saída é o apoio financeiro do CDB e do China Exim Bank, pelo menos no que diz respeito às atividades de grandes empresas estatais e estatais que compõem a maior parte do investimento estrangeiro direto da China (IDE)"'14.Em outros termos, a partir da análise qualitativa dos dados quantitativos expostos nas sessões anteriores, o cruzamento entre valores, natureza e atividade econômica dos setores-alvo enseja novas interpretações sobre o IED chinês no SE Asiático e na América do Sul e sua expansão econômica - mas também geopolítica - nas duas áreas.

Referente ao Sudeste Asiático, além dos investimentos corresponderem a uma lógica econômica em sua zona de influência imediata, em que empresas chinesas e ETN's com sede na China deslocam partes de suas cadeias produtivas em busca de redução de custos, agregam-se fatores político/estratégicos para a execução dos projetos. O foco dos Estados Unidos na Guerra ao Terror ensejou maior participação da China em seu entorno estratégico, tornando-se o maior parceiro político e econômico dos países da região, exercendo influência diplomática e militar, além da atuação como motor do desenvolvimento regional, seja através de projetos de integração regional e de infraestrutura ou dos déficits comerciais com alguns países, além do crescente investimento externo direto.

Há também fatores históricos em jogo: a China tem historicamente muita influência no SE Asiático e sua política externa tem instrumentalizado um passado de centralidade cultural benigna para passar a imagem da ascensão pacífica. Até mesmo o slogan do governo de Xi Jinping, o "Sonho Chinês", traz consigo uma versão repaginada de uma Ásia Oriental estável e pujante, onde a diáspora chinesa na região tenderia a cumprir, assim como no passado, papel importante nos negócios.

No caso da América do Sul, o crescente aumento do IED a partir dos anos 2000 se justifica pela lógica de Estado chinês em sua estratégia de maior inserção internacional (going global) e de uma nova etapa de desenvolvimento, no qual tais investimentos buscam, principalmente, o acesso aos recursos naturais estratégicos da região, assim como a seus mercados via expansão de suas empresas multinacionais, o preenchimento do histórico gap infraestrutural sul-americano via financiamentos e projetos e, em certa medida, o acesso a tecnologia e conhecimento técnico, tomando como exemplo as participações chinesas nas concessões realizadas pela Petrobras, mundialmente conhecida como uma das empresas mais qualificadas no setor e com know-how em extração de petróleo em águas profundas.

Ainda, sob uma lógica geopolítica, alguns fatores fizeram com que a América do Sul entrasse no radar de influência estratégica da China no sistema mundial. Dentre eles, o vácuo de poder dos Estados Unidos (que desde o século XIX exercia influência direta e indireta na região) a partir de 2001; a emergência de governos progressistas de esquerda e centro-esquerda a partir de 1999 (que contestavam em grande medida a ingerência estadunidense na região, buscando novos parceiros econômicos e políti- 
cos); o retorno da multipolaridade a partir de novos centros econômicos emergentes (no qual os BRICS são o exemplo mais emblemático).

A partir desses fatores, reitera-se a hipótese central de que o IED chinês não obedece a uma lógica pura e simples de mercado, mas é estabelecida e direcionada por um planejamento estatal que leva em consideração múltiplos fatores na execução de seus investimentos no mundo.

Uma vez que a dialética do IED implica não somente o investimento ou financiamento via transferência de recursos, mas também a aquisição do controle e participação da estrutura organizacional da empresa, este processo se difunde para além de um viés econômico, englobando uma lógica de poder que, no caso chinês, corresponde a lógica de Estado pautado nas sucessivas estratégias de maior inserção e participação no cenário internacional; um investimento estatal realizado por razões políticas, diplomáticas, militares e, como nos casos analisados, geopolíticas.

Uma vez que o poder é assimétrico ${ }^{15}$, relativo $^{16}$ e expansivo ${ }^{17}$, os investimentos estrangeiros chineses se inserem numa competição acumulativa contínua pela conquista de novos espaços. A partir de uma lógica de planejamento do Estado chinês, a contextualização sobre a internacionalização de capitais chineses ratifica uma estratégia estatal de médio-longo prazo que visa estabelecer as conexões para as vias de desenvolvimento futuro chinês, angariando e estabelecendo as suas bases de sustentação.

Considerações finais

A escolha do IED como análise de atuação estatal chinesa no sistema internacional é ratificada a partir da própria lógica de IED estatal, uma lógica de Estado e projeto estratégico chinês baseado na "ação dentro da não-ação", que se inicia com a estratégia de going global do começo da década de 2000, alavancado, inclusive, pela entrada da China na OMC em 2001. Em outros termos, num espaço de uma década, a China deixa de ser apenas receptora e passa a ser também exportadora de IED, cuja lógica de Estado necessariamente entra no jogo estratégico.

$\mathrm{O}$ artigo buscou analisar os fluxos de IED chinês tanto no Sudeste Asiático como na América do Sul a partir de dados quantitativos e qualitativos, buscando através do cruzamento de dados entre valores, natureza e atividade econômica propor uma análise dos referidos investimentos para a lógica de Estado da China. Nossa hipótese central se confirma a partir de alguns dados expostos ao longo do presente trabalho: da proporção de investimentos por áreas específicas, praticamente 50\% do IED está voltado para energia, enquanto que entre $33-39 \%$ para metais e transportes. Além disso, mais de $90 \%$ das empresas que investiram no SE Asiático e na América do sul são estatais.

Nos dois continentes analisados nota-se um padrão de busca da China por recursos primários. No SE Asiático há maior complexidade com o deslocamento de cadeias produtivas em busca de redução de custos, mas a atuação em setores de energia continua como a norma. Na América do Sul, os fluxos de IED são realizados por motivos de aprovisionamento de recursos naturais, exportação de tecnologia chinesa e maior atuação geopolítica na região a partir do vácuo de poder dos EUA pós-11 de setembro.
15. "Se todos tivessem o mesmo poder, não haveria disputa nem haveria "relações de poder"." (FIORI, 2014, p.18)

16. “0 poder envolve uma hierarquia e um cabo de guerra permanente entre algum vértice que tenha mais poder $\mathrm{e}$ outro que terá necessariamente menos poder. Se um desses vértices aumentar seus graus de liberdade, algum outro perderá poder, inevitavelmente, com relação ao que se expandiu." (FIORI, 2014, p.18)

17. “Cada unidade de poder (P1, P2, P3 etc) exerce uma pressão competitiva sobre si mesma, e todas essas unidades exercem a mesma pressão umas em relação às outras. Como conseqüência, o sistema, como um todo, também se expande de forma contínua." (FIORI, 2014, p.19) 
Assim, tanto em seu entorno estratégico no Sudeste Asiático quanto em sua área de expansão capitalista sul-americana, a China leva à cabo uma dinâmica que vai além da obtenção de lucros de curto prazo e é motivada por uma lógica estatal que atende a objetivos políticos e estratégicos.

Referências

ACHARYA, Amitav. Constructing a Security Community in Southeast Asia: ASEAN and the problem ofregional order. Nova York, Routledge, 2009.

ASEANstats Database. ASEANstats Jakarta, 2017. Disponível em: < https://www.aseanstats. org/> Acesso em: 18 abr.2018

CEPAL. Chinese Foreign Investment in Latin America and the Caribbean. Santiago, WorkingDocument, 2013.

CINTRA, Marcos A. M; PINTO, Eduardo C. China em transformação: transição e estratégias de desenvolvimento. Revista de Economia Política, vol. 37, n. 2 , 2017.

FIORI, Jose Luis. História, estratégia e desenvolvimento: para uma geopolítica do capitalismo. São Paulo, Boitempo, 2014

FIORI, José Luís. O poder global: e a nova geopolítica das nações, São Paulo, Boitempo, 2007.

FRANK, Andre Gunder. ReOrient: Global Economy in the Asian Age. Berkeley, University Of California Press, 1998.

GALLAGHER, Kevin. The China Triangle: Latin America's China boom and the fate of the Washington Consensus. New York, Oxford University Press, 2016.

HENDLER, Bruno; NOGUEIRA, Isabela. O Sudeste Asiático entre Estados Unidos e China: "arquipélago de economias de mercado" ou palco da competição interestatal capitalista? Carta Internacional, Belo Horizonte, v. 11, n. 3, p.199-221, 2016.

KRUGMAN, Paul R.; OBSTFELD, Maurice. Economia Internacional: teoria e política. São Paulo, Makron Books, 1999

LAI, Hongyi; KANG, Su-jeong."Economic Development and China's Foreign Policy”. In.: KAVALSKY, Emilian (ed.). The Ashgate Research Companion to Chinese Foreign Policy. Surrey, Ashgate, 2012. p.113-121.

MEDEIROS, Carlos Aguiar de. A China como um duplo pólo na economia mundial e a recentralização da economia asiática. Revista de Economia Política, São Paulo, v. 26, n. 3, 2006.

MEDEIROS, C. Desenvolvimento econômico e ascensão nacional: rupturas e transições na Rússia e China. In: O mito do colapso do poder americano. Rio de Janeiro, Record, 2008.

OCDE Statistics, Paris, 2017 . Disponível em: <http://www.oecd.org/corporate/mne/statistics.htm>.Acesso em: 18 abr.2018.

PEI, Changhong; ZHENG, Wen. China's Outbound Foreign Direct Investment Promotion System, Nova York, Springer, 2015.

PINTO, Eduardo C. A integração econômica entre a China e o Vietnã: estratégia china plus one, investimentos e cadeias globais. In: CINTRA, Marcos; FILHO, Edison; PINTO, Eduardo (orgs.). China em transformação: dimensões econômicas e geopolíticas do desenvolvimento. Rio de Janeiro, IPEA, 2015.

SAMBATH, Phou. Cambodia-China Relation: Past, Present and Future. Sem data. Disponível em:<http://www.ncku.edu.tw/cseas/98CSEAS/report\%20SEA/CAM/cam11\%20phou\%20 sambath.pdf $>$ Acesso em : 18 abr.2018.

SANDRONI, Paulo. Dicionário de economia do século XXI. Rio de Janeiro, Record, 2008

SHI, Yinhong. "The impact of China's capitalist transition on foreign policy”. IN.:McNALLY, Christopher (ed.). China's Emergent Political Economy: capitalism in the dragon's lair. Londres, Routledge, 2008. p.209-227.

SLIPAK, Ariel M. América Latina y China: cooperación Sur-Sur o Consenso de Beijing? Lima, Nueva Sociedad, v. 250, p.102-113, mar./abr. 2014.

SPRINGER, Cecilia. The China-Indonesia Energy Entanglement Moves in a New Direction. Singapore, YusofIshak Institute, n. 13, 2016. 
SUTTER, Robert. Chinese Foreign Relations: Power and Policy since the Cold War. New York, Rowman and Littlefield Publishers, 2012.

TSAI, Tung-Chieh; LIU, Tony Tai-Ting."China's Relations with Latin America”. IN.: KAVALSKY, Emilian (ed.). The Ashgate Research Companion to Chinese Foreign Policy. Surrey, Ashgate, 2012. p.287-298.

VADELL, Javier. A China na América do Sul e as implicações geopolíticas do Consenso do Pacífico. Revista Sociologia Política, Curitiba, v. 19, p.57-79, nov. 2011.

YAO, Shujie. WANG, Pan. China's Outward Foreign Direct Investments and Impact on the World Economy. Londres, Palgrave Macmillan, 2014.

ZHANG, Baijia. The Path of the CPC: Revolution, Construction and Reform. Beijing, Foreign Languages Press, 2012 